\title{
○
}

\section{THE COMPUTER SCIENCE UNDERGRADS HELPING FARMERS ADOPT SUSTAINABLE FARMING PRACTICES}

MOST OF THE FOOD PRODUCTS WE HUMANS CONSUME EACH DAY HAVE, AT SOME POINT IN THE PRODUCTION CYCLE, BEEN SPRAYED WITH PESTICIDES TO PROTECT AGAINST DAMAGE CAUSED BY PESTS. DR CHRISTIAN NANSEN RESEARCHES HOW PEST MANAGEMENT, BASED ON PESTICIDE APPLICATIONS, CAN BE OPTIMISED TO ENSURE BOTH PROFITABILLTY AND SUSTAINABILITY. TO PUT HIS RESEARCH INTO PRACTICE, PROFITABILITY AND SUSTAINABILITY. TO PUT HIS RESEARCH INTO PRACTE HE ENLISTED THE HELP OF TWO COMPUTER SCIENCE UNDERGRADUATE STUDENTS TO DEVELOP THE INNOVATIVE SMART SPRAY APP,
FARMERS DECIDE WHEN AND WHERE TO APPLY PESTICIDES

PEgT MANAGEMENT AND THE DECISION-MAKING PROCESS

Imagine being the manager/owner of a farm with several individual strawberry fields - all of them larger than five soccer fields, meaning there is a lot of high-value crop under your management.
You have a worker helping you with crop scouting: on a regular basis, the worker walks into the fields and looks for crop damage by pests. the worker walks into the fields and looks for crop damage by pests.
At some point, your worker finds 'hot spots' in some of the fields (groups of strawberry plants) with emerging outbreaks of a pest yo be considered when making a decision on how to respond to such be considered when making a
pest outbreak in a crop field?

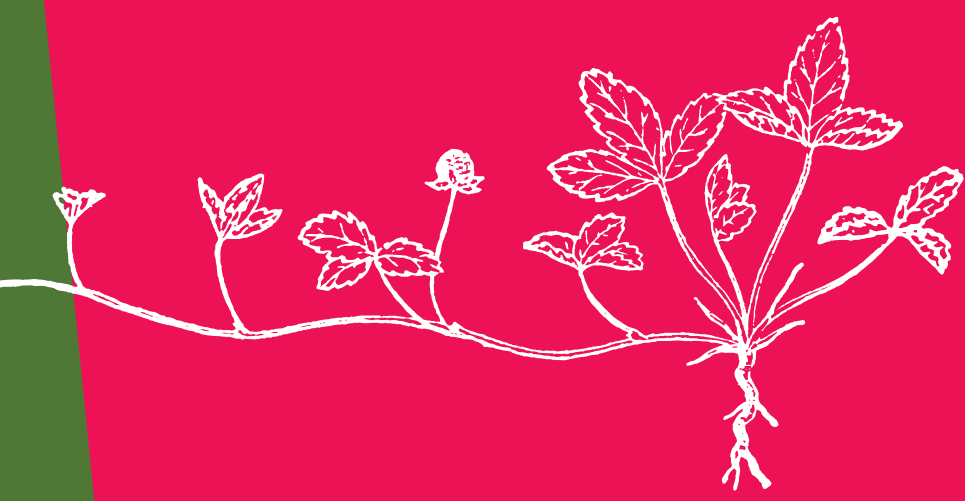

It takes time and labour costs to perform crop scouting, so there will be a limit to how much crop scouting can be performed. But without crop scouting, farmers won't know whether they have
pest outbreaks - so, what is the optimum level of scouting? Is it possible that the worker performing the crop scouting missed some emerging hot spots of pest outbreaks?

Applications of pesticides to control pest outbreaks require spraying equipment, labour, chemicals, fuel and other
expenditures - so, pesticides should not be applied unk necessary. But should the whole field be sprayed or only portion of fields? For instance, only the detected hot spots?

Agricultural pests, such as insects causing crop damage, are known to develop resistance to pesticides. Once that happens, a particular pesticide is no longer effective against a given pest. So, the only real way to minimise the risk of pest populations developing resistance is by only using pesticides when they are causing significant crop damage. But how is that determined?
And what if the prediction of risk of the pest causing significan crop damage is wrong?

There are regulations/restrictions on how many times crops can be sprayed with specific pesticides, and applying one pesticide to
control one pest may in some cases also kill 'beneficial insects'

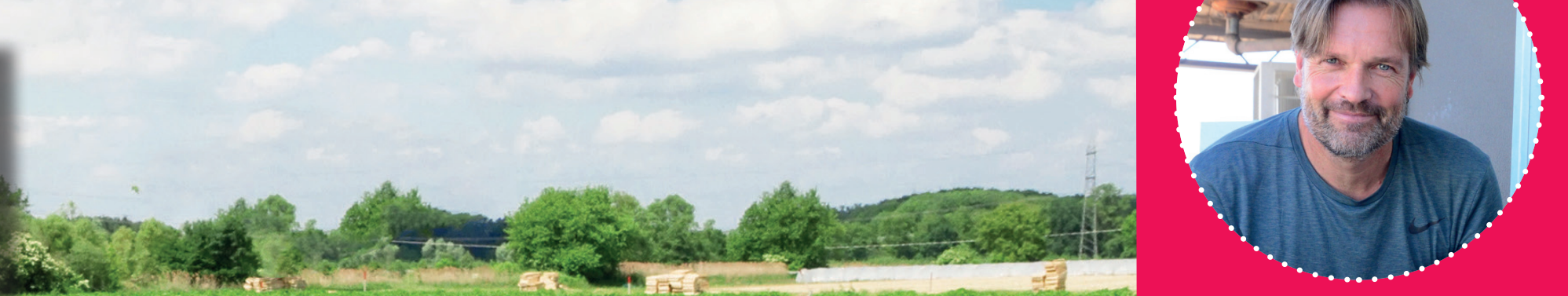

DR ChRistian nansen

Associate Professor, Entomology and Environment,

FIELD OF RESEARCH

Insect ecology, sustainable pest

n.........

RESEARCH PROJECT

Using innovative technologies
to develop methods of targeted pesticide application.

FUNDERS

pest species). It is possible that applying one pesticide to control pest $A$ causes world, as the 'side effects' of drug treatments. So, which pesticide should be applied? And if you decide to apply a pesticide that can only be applied once to a given crop per season
growing season?

- Finally, if we assume that it is deemed necessary to apply a certain pesticide, what factors may affect the performance (how well the pest outbreak was controlled) of a particular pesticide application? The farmer needs to select the right spraying equipment as well as consider how weather conditions might affect the pesticide spplication performance. For example, what do you think happens fin aplication is performed under dry and windy conditions?

As you can hopefully appreciate from this brief introduction about the decisionmaking process associated with pest management, there are lots of factors to take into account, and making the 'right' decision is difficult. Also, the possible consequences of making the 'wrong' decision can be very costly - either wasting money on pesticide applications that were not necessary or losing money because similarities in decision-making between the medical diagnostics of our own health and the diagnostics used to successfully manage risks of pest outbreaks in farming systems. Just as doctors in the health care sector need equipment and guidelines to
make decisions - these are generally referred to make decisions - these are generally referred to as decision support tools - applied research in pest management is heavily geared towards developing user-friendly and reliable decision support tools for farmers. This article is about such a decision support the which was developed in collaboration with undergraduate students.

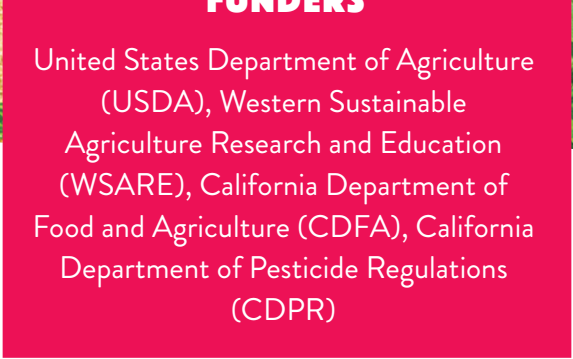

The decision support tool is in fact a smartphone app, which has been developed and offered freely to farmers to help them make challenging decisions on how to smartphone technologies like these can make farming so much better for people and the environment, we begin by peeling back some of the 'layers' involved in food production. Think of it like peeling an onion. First, we investigate why crop pests are such a problem; moving on, we find out how humanity has dealt with such pests historically; then, we examine how modern solutions could be better; and then we consider technologies that can help usher in these new solutions, such as the Smart Spray app that $\operatorname{Dr}$ Christian Nansen and his team in people from a range of backgrounds has what opportunities might lie in store for you to get involved. optimise pesticide applications. To unpack why developed. Finally, we look at how bringing benefited sustainable pest management and

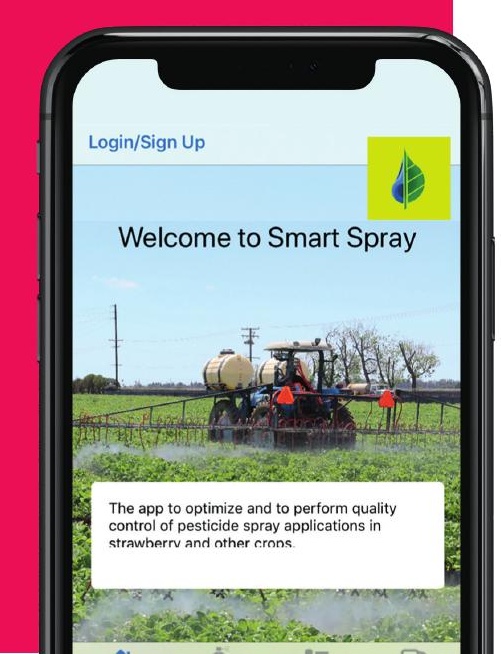


OUIER LAYER OF THE ONIONE Pests: why are they a problem?

\section{SECOND LAYER}

How did we deal with pests?

PESTS AND FOOD PRODUCTION Most historians agree that the advent of civilisation is marked by the development of agriculture. Having a reliable food production system is central for society. However, agriculture is no easy ride; uncertainties sector to work in. The impact of pests is on addressed. Among major global food crops, pests and pathogens (disease-causing organisms) decrease yields by $10-40 \%$. Agricultural crop pests can be any animal, plant or microbe that directly damages crops and causes a yield loss. There are wide range of pests for any crop and it is difficult to predict which will cause problems in any given year. There are many ways
to both minimise risk of pest outbreaks in crops (preventive measures) or respond (responsive measures). Among responsive measures, farmers can release/spread natura enemies, which are insects that are known to control specific pest insects. An example is lady bugs, which are known to feed on aphid pests. Use of natural enemies in pest control. Another category of responsive measures is applications of pesticides, and in most farming systems this is the most widely used responsive approach to pest outbreaks.

THE COMPLEX ISSUE OF PESTICIDES As their name suggests, pesticides are chemicals that kill pests. They can be extremely effective and can cause dramatic declines in pest numbers. People have been using pesticides in one form or another for thousands of years. The earliest know insects. From the 15 th century until the 950s, arsenic was the principal compone improvements were a central part of the 'Green Revolution' in the 1970s, where and crop breeding boosted crop yields and prevented mass starvation. They have seen used extensively in agriculture ever since. However, despite their contribution
to productivity, pesticides are certainly not without their downsides. For instance, to the collapse of bee colonies. Bees and many crops but also integral for ecosystem becoming highly restricted in the EU and elsewhere.

Pesticides applied to a crop field can also impact surrounding areas, either by blowing in the wind (referred to as 'spray washed away by rainfall. The risk of spray drift is mainly caused by a combination of unfavourable weather conditions (high wind and low humidity) and pesticide droplets being so small that they can easily drift aw and enter neighbouring water bodies and it may cause pollution and harm to nontarget organisms and, secondly, it means

The and esource for the farmer.

account for. For example, spray drift fo account for. For example, spray drift from may end up with pesticides on their skin whether pesticide residues left on food have an adverse effect on people's health but, certainly, their presence reduces the food's appeal to the consumer. such as weather, diseases and fluctuating
demand can make it a highly unpredictable such significant uncertainty, as outbreaks can decimate crop yields if not properly to emerging or established pest outbreaks management is referred to as biological example is from ancient Mesopotamians who dusted their crops with sulphur to deter

\section{THIRD LAYERZ}

Are there other ways to deal with pests?

\section{FOURHH LAYER:}

The Smart Spray app

\section{FIFH LAYER/ONION CORF}

How might you get involved?

f dominant pesticides, but since then they have become more sophisticated. Pesticide advances in technology, synthetic chemical neonicotinoids is a group of pesticides, whose other pollinators are not only beneficial to function. This has led to neonicotinoid usa the pesticide is blown away from where it is widespread use has been partially linked drift'), leaching into ground water or being fields, woodlands and urban areas. Spray drift is a problem for two main reasons: firstly, time and resource for the farm may to urban areas means that residents
SUSTAINABLE PEST MANAGEMENT Widespread and frequent pesticide applications is therefore not a sustainable solution - but what are the alternatives? A more in-depth knowledge of how crops and ecosystems work is needed to answer this. Agricultural science has advanced in leaps and bounds in recent years and we now have a much deeper understanding of how to suppress pests without relying exclusively pesticide applications.

One important point that has become increasingly clear is that merely using less pesticide (lower dosage) isn't a solution unless approached very carefully. Low or inconsistent pesticide spray coverage may not only result in poor pest control - it can also increase the risk of pests becoming resistant to pesticides. If pests are only exposed to a low dosage of pesticide, only the most susceptible are killed. Those that survive will have some tolerance to the pesticide - and they're the ones that reproduce, passing on their genes for tolerance to the next generation. This process, known as resistance evolution, can lead to particular pesticides becoming useless against pests. The same thing can happen with antibiotics in humans. To combat the emergence of resistant bacteria, doctors always recommend that you finish a course of antibiotics.

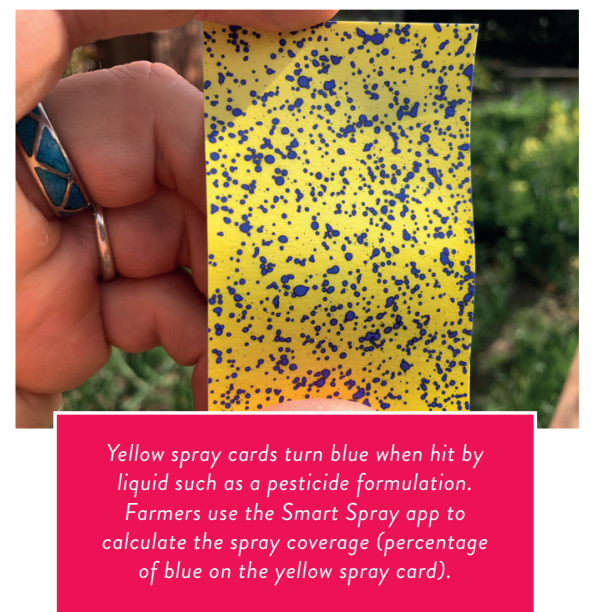

$2=2 x^{2}+2 x-5$
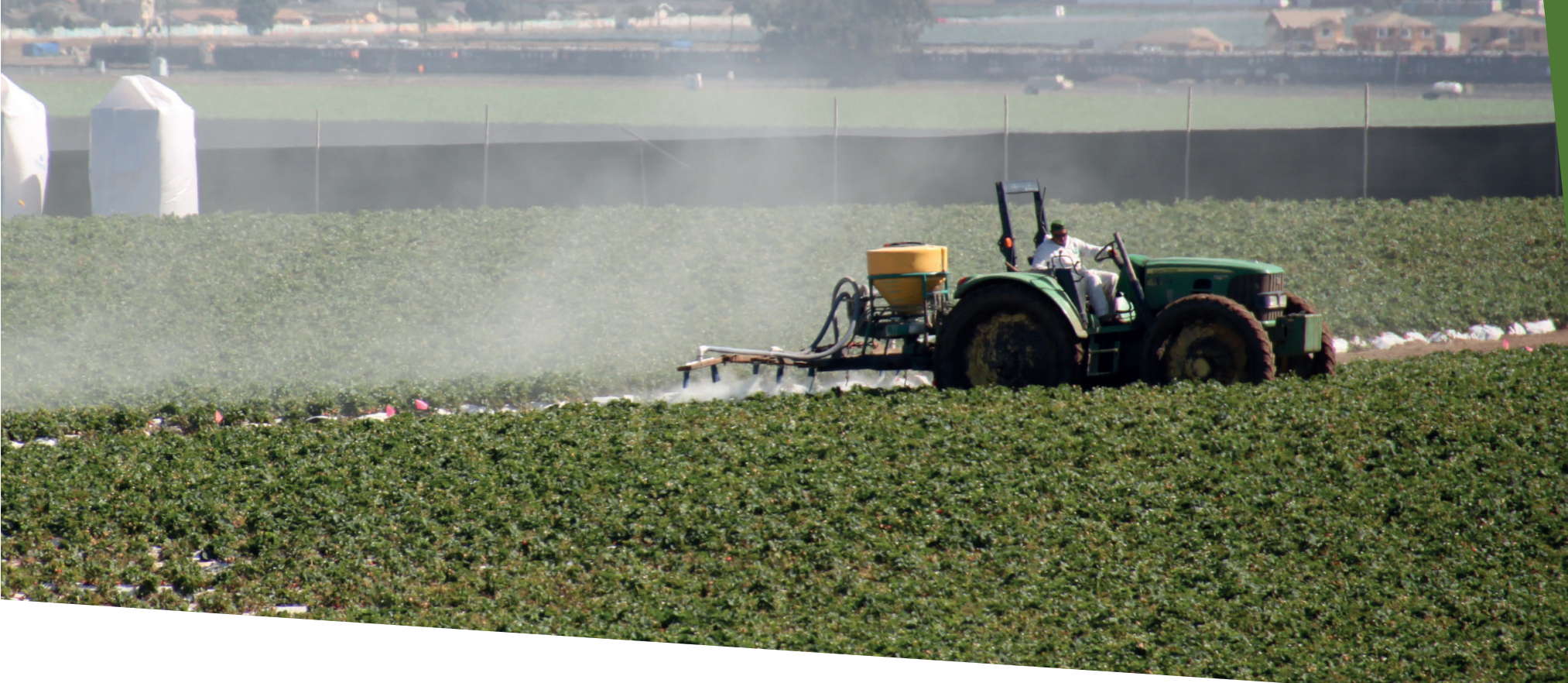

So, reducing the amount of pesticides used needs some very careful thought. The to prevent resistance evolution. How do the amount they use? Making sure that pesticides are used in the most effective and environmentally-friendly way possible is a key step in making agriculture more sustainable.

TRAINING TECHNOLOGY echnology, coupled with scientific understanding, is a key part of solving this puzzle. Christian is one such researcher computer science students, is using
smartphone technology as a platform for smartphone technology as a platform for decision support tools to farmers. They have developed a smartphone app called 'Smart Spray', which helps farmers optimise when and how to apply pesticides. Smart Spray uses a predictive computer model. This means that the user feeds information into the Smart Spray app, whic then generates predictions of spray coverage you want to know what the wether might you want to know what the weather might be like in a certain place on a given day, the predictive modelling to provide $y$ ou with predictive mode

Perhaps surprisingly, a predictive computer pesticide has to kill almost all pests in order farmers achieve this if they are to reduce who, along with a team of undergraduate
This involves feeding in 'template' information - telling the model which inputs lead to which outputs. For a weather app, for example, this information comes from vast data banks documenting how certain conditions - such as atmospheric pressure lead to certain weather outcomes.

To train the models in the Smart Spray ap Christian's team collected field data from spray cards that change colour when they get wet from the pesticide spray. These cards were placed at various locations throughout strawberry fields. The team then recorded the outcomes of a range of different note of what happened when different spray nozzles were used or when the weather was good or bad. Once a large number of different scenarios had been recorded, predictions.

Simply recording the outcomes of a fow scenarios isn't nough for the model tow will how isn't nough for the model to work variabes So, he tam record a vot of such as different weather conditions, the size of strawberry plants and how they were grow, the type of spraying equipment used, speed of the tractor. For each scenario, they neted the colour chores on scenario, they - which indicted how muth of the pestide had he findings into the model's traning pesticide scenarios: for example, making
SMART SPRAY

The Smart Spray app can help farmers use pesticides in ways that minimise the risks profry difr and maximise their ability to protect crops from pests. The app has two 政 show how sucy soverage needed as well as

The app's predictive function runs algorithms after users of the app have entered information about the crop, weather conditions and other operational settings. To fully understand how the app works, we Android or IOS app store - simply search for with a droplet/leaf. You can also download a manual and follow down load instructions on this website. hthp.//chrnansen.wixsite.com/ nansen $2 /$ smartspray.

Smart Spray has been designed for strawberry growers, but the team plans to adapt it for other crops, such as almond, pistachio and tomato. As well as benefiting the app means that less pe. Most obviously, applied, so fewer non taret or anis will speffer. Addition lly, the app onf is s will to dely spraying if the app in forms farmes weather conditions that would resul in pesticide spray drift. encourage you to download it from the "Smart Spray" and look for a yellow symbol farmers' pockets, it is also good news from 
I got involved in the Smart Spray project when Dr Nansen reached out to the Computer Science Department at the university. I had some experience as a mobile developer, so it seemed like a good fit. I was curious to see how technology would be used in other fields and this was the perfect way to explore that.

It is thanks to an unusual collaboration that Christian was able to develop the Smart Spray app. Building the app was beyond the scope of agricultural scientists or entomologists (people who study insects), such as Christian. Teaming up with computer science undergraduate students provided a unique solution. Christian provided the agricultural expertise,
their coding skills to build the app's digital structure and user interface.

Gabriel and Alexander are computer science undergraduate students at the University of California Davis in the USA. They tell us how they ented

\section{GABRIEL DEL VILLAR DE SANTIAGO}

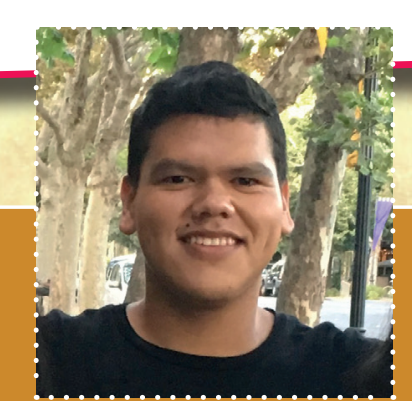

A fellow computer science undergraduate recommended that I apply to work with Christian on the Smart Spray app. I have an interest in health and welliness, and I care about where the food $I$ eat comes from. Additionally, I wanted to learn more about the processes behind growing, cultivating and
bringing foods to market. My generalist mindset means thet I m interested in how technology can be applied to solve problems outside of pure computer science.

I led the development of the iOS version of the Smart Spray app and was heavily involved at every stage of the process. This included launching the app on the Apple App Store, prototyping future versions of the app and helping to improve the undenlying algort

One of the most challenging aspects of designing the app was ensuring it was easily scalable. We wanted to be able to efficiently add more crops and features in the future. Because the app caters to user interface that caters to a very specific use.

It is a source of pride for me that the merging of two disciplines - application development and entomology - gave us the tools to solve problems for sustainable agriculture. Working with Dr Nansen was a fun and rewarding experience, and it feels fantastic to have had a positive impact.

I have always taken an interest in development and design. I have wanted to be an engineer or architect from a young age. During school, lenjoyed solving problems using technology, so computer science seemed like the ideal path for me.

Once I graduate, I hope to use my degree to build apps to benefit the health and wellness sector. This could mean building software for sustainable food production, for hospitals, or to help people your skills to a wide variety of disciplines. If you enjoy creativity, critical thinking and problem solving your skills to a wide variety of discip

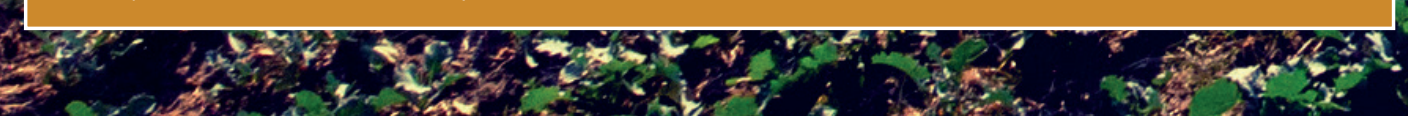

I developed the Android version of the app, so Gabriel and I worked closely together. We wanted our app versions to behave identically, and it also helped to collaborate on problem solving. For instance,

At first, it was a challenge to not have a senior person telling me exactly what to do. I had to teach myself how to finish each task on my own. Although this was challenging, it was a good learning have a tool to help optimise pesticide application, which has led to lower pesticide usage on crops tes contamination of the environment. This is a great source of pride for me.

When I was younger, I wanted to be an astronaut or an inventor. After that I wanted to be a I wanted to specifically become a software engineer. I had started coding years before, right fel watching The Matrix at 9 years old. I began by coding a basic rock-paper-scissors game and fell in ove. By the time I reached high school I was coding non-stop.

have a job lined up for when I graduate. I will be working for a company called Esri which designs Geographic Information Systems (GIS). My work will be fit farmers but vill not be as focused as this project. I will probably move back into agricultural technology eventually, but the start of my
to career will be more general.

Working with Dr Nansen was a great experience. It gave me the opportunity to see how technology can be applied to different fields. I went to a farmers' conference, where I learnt how technology is being used throughout agriculture.

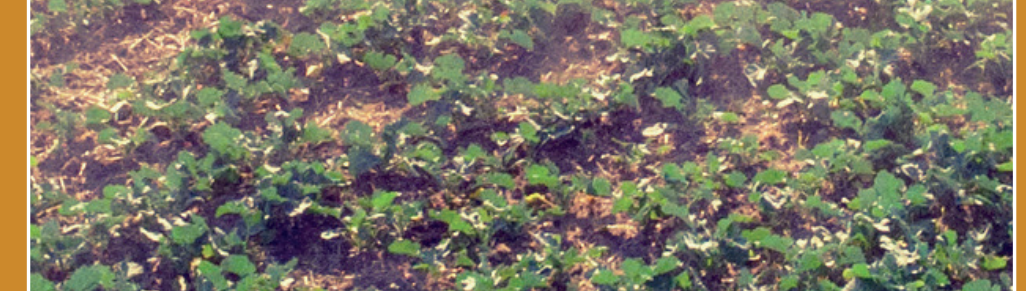

I would advise trying out coding before beginning a computer science class. I know a lot of people who dropped out of computer science classes because they did not enjoy coding. Although it's fun to
do coding for coding's sake, it's often more fun to do your own project. There are plenty of resouces out there where you can design your own website or app and beginning with these tutorials is a great first step. Even when I had difficult or boring class assignments, I never quit beceuse I knew how mch fun taking a project through to completion could be.

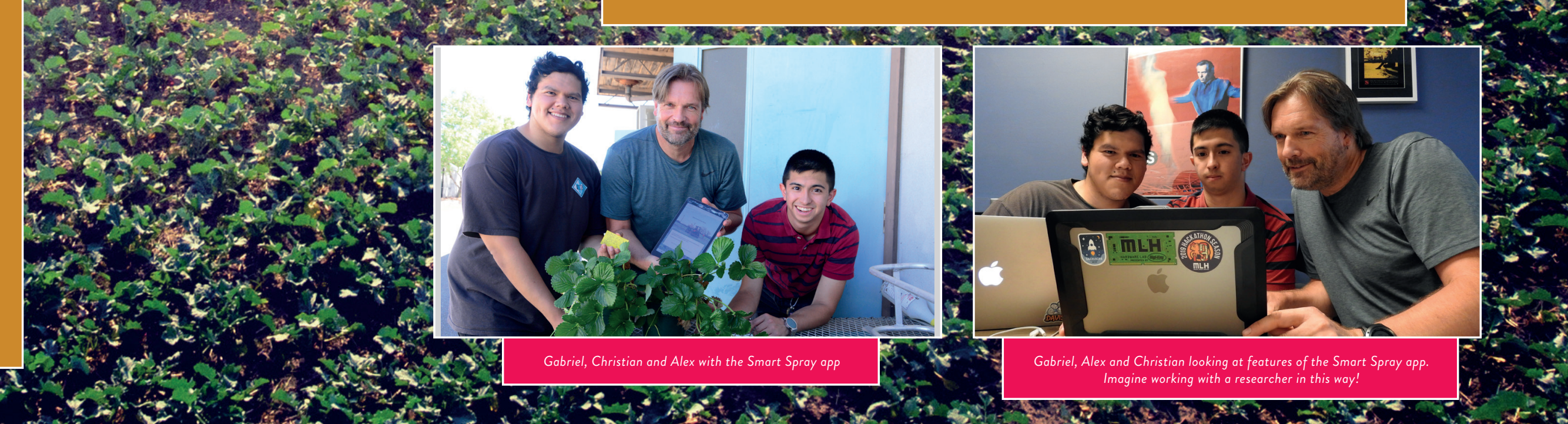

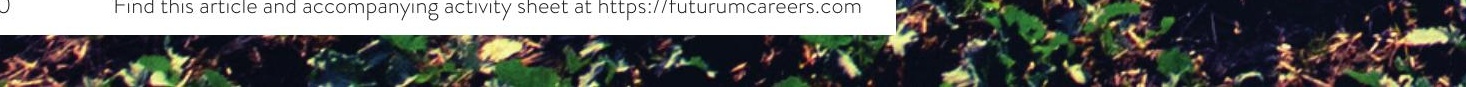




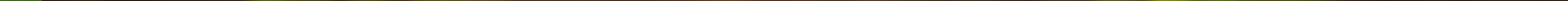

